\title{
EFFECTS OF EARTHWORM (EISENIA FETIDA) AND WHEAT (TRITICUM AESTIVUM) STRAW ADDITIONS ON SELECTED PROPERTIES OF PETROLEUM-CONTAMINATED SOILS
}

\author{
MAC A. CALlAHAM, jR., *t ARTHUR J. STEWART^ ${ }^{\wedge}$ CLARA ALARCON, \pm and SARA J. MCMILLEN $\S$ \\ tEnvironmental Sciences Division, Oak Ridge National Laboratory, Oak Ridge, Tennessee 37831, USA \\ ${ }^{\wedge}$ Ecology and Environmental Department, PDVSA Intevep, P.O. Box 76343, Caracas 1070-A, Venezuela \\ $\S$ Chevron Corporation, Chevron Research and Technology, 100 Chevron Way, Richmond, California 94802, USA
}

(Received 3 October 2001; Accepted 12 December 2001)

\begin{abstract}
Current bioremediation techniques for petroleum-contaminated soils are designed to remove contaminants as quickly and efficiently as possible, but not necessarily with postremediation soil biological quality as a primary objective. To test a simple postbioremediation technique, we added earthworms (Eisenia fetidd) or wheat (Triticum aestivum) straw to petroleum land-farm soil and measured biological quality of the soil as responses in plant growth, soil respiration, and oil and grease (O\&G) and total petroleum hydrocarbon (TPH) concentrations. Results indicated that plant growth was greater in earthworm-treated land-farm soil. Furthermore, addition of wheat straw resulted in greater total respiration in all soils tested (land-farm soil, noncontaminated reference soil, and a 1:1 mixture of land-farm and reference soils). We observed a 30\% increase in soil respiration in straw-amended oily soil, whereas respiration increased by $246 \%$ in straw-amended reference soil. Much of the difference between oily and reference soils was attributable to higher basal respiration rates of nonamended oily soil compared to nonamended reference soil. Addition of earthworms resulted in greater total respiration of all soil and straw treatments except two (the land-farm and the 1:1 mixture soil treatments without straw). Straw and earthworm treatments did not affect O\&G or TPH concentrations. Nevertheless, our findings that earthworm additions improved plant growth and that straw additions enhanced microbial activity in land-farm soil suggest that these treatments may be compatible with plant-based remediation techniques currently under evaluation in field trials, and could reduce the time required to restore soil ecosystem function.
\end{abstract}

Keywords-Petroleum Bioremediation Earthworms Soil respiration

\section{INTRODUCTION}

Petroleum land farms are sites where waste petroleum hydrocarbons are biotxeated by direct application to the soil surface. The materials are tilled into the soil, along with nutrients, to encourage biodegradation of the hydrocarbons by soil microbes. Soil bulking agents (e.g., sawdust, wood chips, and manure) and gypsum usually are applied as well, to improve ion balance and physical properties of the soil. One problem associated with petroleum land farms is that although lower molecular weight petroleum compounds volatize or are biodegraded efficiently, higher molecular weight petroleum compounds tend to biodegrade much more slowly. Thus, a result of continued application of petroleum hydrocarbons to landfarm soils is the gradual accumulation of high molecular weight petroleum compounds. In soils, higher molecular weight petroleum hydrocarbons (e.g., $>\mathrm{C}_{22}$ ) tend to be less toxic or less biologically available than the lower molecular weight compounds (e.g., benzene, toluene, ethylbenzene, and xylene) $[1,2]$. However, at high concentrations, the high molecular weight constituents of petroleum can increase soil water repellency, which can in turn affect the growth of plants. As a result, bioremediated oily soils may be less productive than desired, and may not support a diverse community of organisms (plants, soil invertebrates, and so on) [3].

Ultimately, with repeated applications, the concentration of

* To whom correspondence may be addressed (mcallaham@fs.fed.us). The current address of Mac A. Callaham, Jr. is USDA Forest Service, 233 Lehotsky Hall, Clemson University, Clemson, SC 29634 USA. petroleum hydrocarbons approaches an upper-bound permitted limit. When this occurs, the land farm can no longer be used for treating additional waste petroleum, and alternative uses for the land are then desired. Given an ultimate goal of returning a land-farm site to productive use, one of the first steps toward this goal would be to improve both the appearance and fertility of the biotreated soil, and to restore native communities of plants and soil invertebrates.

Previous studies have demonstrated that soil bioremediation (of the kind used in conventional petroleum land-farm operations) can substantially improve the biological quality of soils, when soil quality is measured in terms of earthworm survival and reproduction [4,5]. This finding is significant because earthworms are an important component of most healthy soil ecosystems in temperate climates. Indeed, earthworms have been referred to as ecosystem engineers because their burrowing and feeding activities fundamentally alter soil systems, causing space or food resources to be available to other groups of soil organisms that would not be able to survive otherwise [6], Furthermore, it is generally recognized that plant growth is improved when earthworms are present in soils, and many experimental demonstrations of this principle have been done for various ecosystems with various species of earthworms [7-9]. The status of earthworms as ecosystem engineers, and the use of earthworm applications in large-scale land reclamation projects in Europe [10-12] led us to consider earthworms as a possible treatment for improving the biological quality and ecological recovery of soils in the context of petroleum land farms.

- Eisenia fetida is an easily cultured, hardy earthworm spe- 
Table 1. Physical and chemical properties of landfarm soils and .reference soils used in experimental incubations. Values are from analyses performed on representative subsamples of sieved and homogenized soils. All analyses were conducted by Colorado Analytical Laboratories (Brighton, CO, USA)

\begin{tabular}{lcc}
\hline Parameter & Landfarm soil & Reference soil \\
\hline Sand (\%) & 59 & 28 \\
Silt (\%) & 35 & 37 \\
Clay (\%) & 6 & 35 \\
pH (paste) & 7.3 & 8.9 \\
Electrical conductivity (mmho/cm) & 12.1 & 0.7 \\
Organic matter (\%) & 8.0 & 1.1 \\
Cation exchange capacity (meq/100 g) & 19.0 & 19.7 \\
Nitrate N (ppm) & 11.1 & 9.2 \\
Organic N (\%) & 0.40 & 0.19 \\
NH $H_{3}$ (ppm) & $<0.001$ & $<0.001$ \\
Available phosphorus (ppm) & 21.4 & 6.0 \\
Saturated hydraulic conductivity (inches/h) & 1.85 & 0.20 \\
Water retention (moist at 0 bar, \%) & 59.6 & 35.0 \\
Water retention (moist at 0.3 bar, \%) & 23.2 & 25.8 \\
Bulk density (g/ml) & 1.01 & 1.27 \\
\hline
\end{tabular}

cies with a wide range of tolerances for temperature, moisture, and soil $\mathrm{pH}$ [13]. In part because of these attributes, E. fetida is widely recognized for its usefulness in ecotoxicological applications [14] as well as in vermicomposting operations [13]. Additionally, waste material that has been processed by $E$. fetida has been shown to be an excellent substrate for plant growth $[15,16]$. Interestingly, although the short-term (14-d) survival rate of E. fetida is reported to be high even in biotreated soils that contain fairly high concentrations of petroleum hydrocarbons $[1,4]$, the potential for these earthworms to impart benefits to plants growing in oily soils apparently has not been tested. Our objective in this study was to use $E$. fetida as a treatment variable, rather than a response variable, to assess the potential for their use in ecological reclamation of biotreated petroleum-contaminated soils.

\section{MATERIALS AND METHODS}

\section{Soil}

For these experiments, we used soil that had been collected from an operating petroleum land farm in northwestern Colorado, USA.' The primary use of this land farm is treatment of petroleum exploration and production wastes. The soil had not received waste application for several months before use in our studies. Table 1 shows general chemical and physical characteristics of the land-farm soil, and a reference soil collected near the land farm.

\section{Plant growth experiment}

Sieved and homogenized land-farm soil was weighed $(\sim 250 \mathrm{~g}$ wet wt) into plastic cups. Treatments were applied in a completely randomized factorial design of earthworm and straw treatments, totaling four treatment combinations (landfarm soil alone, land-farm soil with wheat [Triticum aestivum] straw, land-farm soil with earthworms, and land-farm soil with both earthworms and wheat straw). There were replicates of each treatment combination. The straw treatment consisted of thoroughly mixing $4 \mathrm{~g}$ of chopped air-dried wheat straw into the soil within each straw-treated cup. The straw treatments were allowed to condition for three weeks before initiation of earthworm treatments. The earthworm treatment consisted of two levels: earthworms present or earthworms absent. Replicates with earthworms present were prepared by adding two adult individuals of $E$. fetida to each cup (average combined fresh wt of $1.5 \mathrm{~g}$ per cup). One week before introduction of earthworms to the experimental units, all cups were planted with four seedlings of tall fescue (Festuca arundinacea). These seedlings were sprouted in vermiculite, and only seedlings of similar size and appearance were used in the experimental units. For the duration of the study, experimental units were wetted to water-holding capacity every $3 \mathrm{~d}$, and were maintained at $18^{\circ} \mathrm{C}$ under 24 -h light (cool-white fluorescent tubes) in an environmental chamber (Conviron, Winnipeg, $\mathrm{MB}$, Canada). After $45 \mathrm{~d}$ of incubation with or without earthworms, all experimental units were destructively sampled and plant material was collected. Plant shoots were cut off at the soil surface and placed into paper bags, dried at $60^{\circ} \mathrm{C}$, and weighed. For each replicate, roots were carefully separated from soil by hand; root material was placed in a paper bag, dried at $60^{\circ} \mathrm{C}$, and weighed.

\section{Soil respiration experiment}

Sieved and homogenized land-farm soil, reference soil (non-land-farm), and a 1:1 (mass basis) mixture of land-farm and reference soils were weighed ( $400 \mathrm{~g}$ dry equivalent) into 0.96-L sealable glass jars. For each of the three soil treatments, four earthworm and straw treatments (no addition, earthworm only, straw only, and both earthworm and straw) were used, resulting in 12 different soil-worm-straw combinations. Five replicate experimental units were used for each treatment combination.

The straw treatment consisted of thoroughly mixing $8 \mathrm{~g}$ of chopped wheat straw into the soil in each jar. The earthworm treatment consisted of adding three adult individuals of $E$. fetida (average combined fresh wt of $-1.65 \mathrm{~g} / \mathrm{jar}$ ) to each earthworm-treated unit. Gravimetric moisture content of soil in experimental units was maintained at approximately $20 \%$ throughout the incubation by adding distilled water to the jars approximately every $3 \mathrm{~d}$ for the first $100 \mathrm{~d}$ of the incubation, and every $7 \mathrm{~d}$ thereafter.

Total respiration $\left(\mathrm{CO}_{2}\right.$ evolution) was measured in each jar every day for the first $3 \mathrm{~d}$, every $3 \mathrm{~d}$ for the next $33 \mathrm{~d}$, and approximately every $7 \mathrm{~d}$ for the next $30 \mathrm{~d}$. A final measurement was made on day 101 . To make the respiration measurements, jars were sealed leak-tight with lids that had been fitted with 
rubber septa, and after $1 \mathrm{~h}$ of incubation with sealed lids, headspace gas samples were taken with a 5-ml syringe. The $\mathrm{CO}_{2}$ concentrations of these samples were determined with a continuous-flow infrared gas analyzer (LiCor Instruments, Lincoln, NE, USA). After measuring respiration on day 101, the experiment was continued (with no further gas sampling) until day 150 . Then, the soils were removed from jars, earthworms (adult and juvenile) were collected and counted, and selected soils were subsampled and analyzed for oil and grease $(O \& G)$ concentrations and gravimetric total petroleum hydrocarbon (TPH) concentrations (U.S. Environmental Protection Agency method 413.1 and method 418.1, respectively). Briefly, O\&G concentrations were determined by extracting $15 \mathrm{~g}$ of the soils for $4 \mathrm{~h}$ with methylene chloride in an accelerated Soxhlet extraction unit followed by gravimetric determination of O\&G. Gravimetric TPH was measured on the same extract, after a silica gel cleanup step to remove polar materials [17].

\section{Statistical analysis}

All data were analyzed with analysis of variance procedures (ANOVA) [18]. Data from the plant growth experiment were subjected to two-way ANOVA with wheat straw and earthworm status as main effects variables. Results from the respiration experiment were subjected to three-way ANOVA with soil treatment, earthworm, and wheat straw as main effects variables. Earthworm survival, O\&G, and TPH data from the soils in the respiration experiment were subjected to two-way ANOVA. Plant growth data and respiration data were logtransformed to satisfy normality assumptions for ANOVA. We used a significance level of $a=0.05$ for all ANOVA results.

\section{RESULTS AND DISCUSSION}

\section{Plant growth}

Plant growth, measured as final dry biomass, was significantly greater in experimental units that contained earthworms (Fig. 1). This increased growth in the presence of earthworms was observed for both shoots and roots. This finding is consistent with other studies where the presence of E. fetida was associated with improved plant performance $[15,16]$. Wheat straw additions had no significant effects on plant growth, but a trend occurred for decreased shoot growth in units with wheat straw present (Fig. 1). This trend may be the result of decreased nutrient availability in straw-treated soils, because nitrogen or other nutrients can become immobilized in recalcitrant substrates (carbon to nitrogen ratio > 100) such as wheat straw $[19,20]$. However, the trend of less growth in wheat straw treatments was not observed for roots of plants grown with both : wheat straw" and earthworms. Earthworms (albeit with species other than E. fetida) have been demonstrated to increase the rate of wheat straw decomposition [21], and this acceleration of straw degradation (i.e., more rapid lowering of the carbon to nitrogen ratio) may be partly responsible for the pattern observed in the straw-plus-worm-treated cups. Our experimental observations suggest that modest nutrient amendments in combination with straw and earthworms might produce the best results in terms of maximum plant growth in land-farm soil.

\section{Soil respiration}

Soil respiration measurements showed that basal respiration rates for nonamended (i.e., without wheat straw) land-farm soil were higher than basal respiration rates of the nonamended reference soil (Table 2 and Fig. 2). This pattern of higher

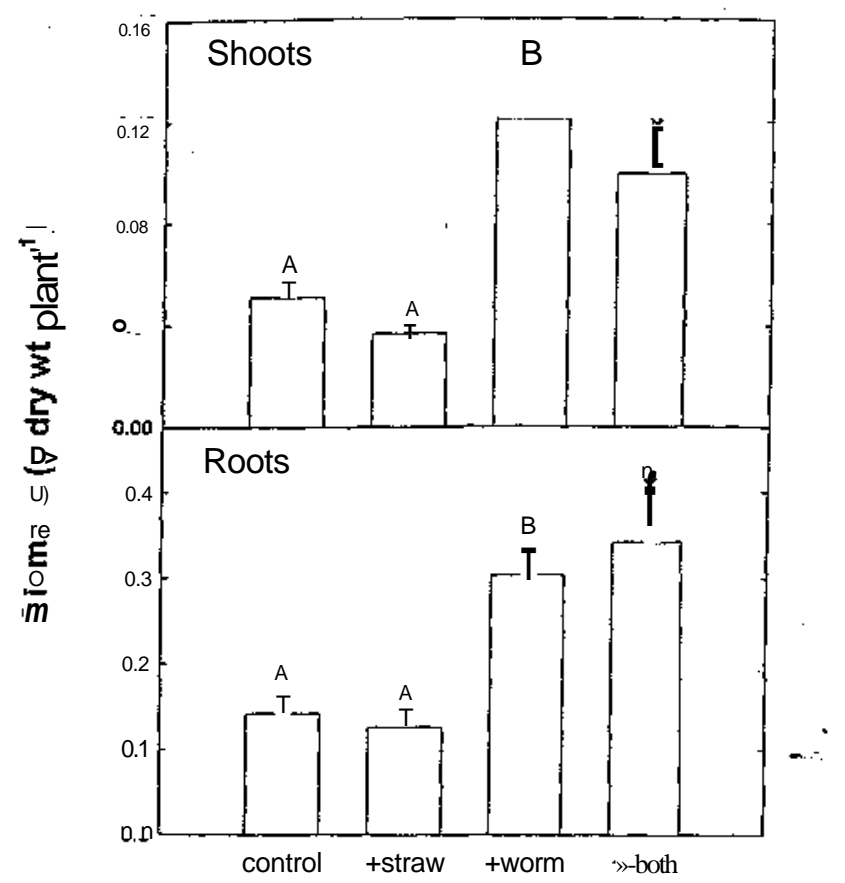

Fig. 1. Tall fescue growth in earthworm-wheat straw factorial experiment: Bars represent mean biomass $(n=5)$ of tall fescue shoots (top panel) and roots (bottom panel) grown in petroleum land-farm soil. Standard error is indicated by error bars. Means with different letters are significantly different from one another (analysis of variance, $p<0.05)$. Note difference in y-axis scales.

respiration in the land-farm soils was almost certainly due to their increased levels of organic material (both petroleum hydrocarbons, as well as soil bulking agents) relative to the reference soils. Several significant treatment interactions occurred in the soil respiration experiment (Table 2). These interactions all involved soil treatment, and are attributable to differences in the magnitude of total soil respiration between soil treatments, because the directional pattern of total respiration was similar for all treatments within a soil treatment (Fig. 2, with exceptions noted below).

The respiration rates for all three soils increased when wheat straw was added, but the reference soils exhibited the greatest amount of increase in respiration rate during the first $30 \mathrm{~d}$ of the incubation (Table 2 and Fig. 2). Over the course of the incubation, we observed a $30 \%$ increase in cumulative soil respiration in straw-amended oily soil, whereas respiration was increased by $246 \%$ in straw-amended reference soil- Much of the difference in respiration response to the straw and earthworm treatments, for the land-farm versus the reference soil, could be accounted for by the higher basal respiration rate of the nonamended land-farm soil, as noted above. We speculate that the smaller response of the land-farm soil respiration to wheat straw addition early in the incubation was the result of either a petroleum-induced depression of the metabolic capacity of microbes in the land-farm soil, or extreme metabolic specialization of the land-farm soil microbial community for petroleum-derived carbon sources, which precluded immediate use of the straw-derived carbon. However, by the end of the 150-d experiment, the cumulative $\mathrm{CO}_{2}$ efflux from the strawtreated land-farm soil was nearly equivalent to that of reference soil, although still with a smaller proportion attributable to wheat straw addition (Fig. 2). Earthworm additions increased respiration rates in all straw-amended soils, but oily soils with- 
Table 2. Results from three-way analysis of variance (ANOVA) of log-transformed data for final cumulative soil respiration data from three soil mixtures experimentally treated with earthworms, wheat straw, neither, or both. Also shown are results from two-way ANOVA testing effects of wheat straw and soil mixture on earthworm survival, and two-way ANOVA testing effects of earthworms and wheat straw on oil and grease and total petroleum hydrocarbon concentrations"

\begin{tabular}{|c|c|c|c|c|}
\hline Source of variation & $d f$ & ss & $F$ & $P$ \\
\hline \multicolumn{5}{|l|}{ Soil respiration } \\
\hline Soil & 2 & 0.4249 & 521.67 & $<0.000 \mathrm{I}$ \\
\hline Worm & 1 & 0.0158 & 38.78 & $<0.0001$ \\
\hline Soil X worm & 2 & 0.0163 & 19.99 & $<0.0001$ \\
\hline Straw & 1 & 1.3832 & 3396.63 & $<0.0001$ \\
\hline Soil X straw & 2 & 0.3919 & 481.14 & $<0.0001$ \\
\hline Worm X straw & 1 & 0.0002 & 0.50 & NS \\
\hline Soil X worm X straw & 2 & 0.0047 & 5.74 & 0.0058 \\
\hline Error & 48 & 0.0195 & & \\
\hline \multicolumn{5}{|l|}{ Earthworm survival } \\
\hline Soil & 2 & 1.1531 & 18.24 & $<0.0001$ \\
\hline Straw & 1 & 0.4343 & 13.74 & 0.0011 \\
\hline Soil X straw & 2 & 0.0079 & 0.13 & NS \\
\hline Error & 24 & 0.7585 & & \\
\hline \multicolumn{5}{|l|}{ Oil and grease } \\
\hline Worm & 1 & 4.4083 & 0.58 & NS \\
\hline Straw & 1 & 0.6750 & 0.09 & NS \\
\hline Worm x straw & 1 & 5.2083 & 0.68 & NS \\
\hline Error & 8 & 61.1333 & & \\
\hline \multicolumn{5}{|c|}{ Total petroleum hydrocarbons } \\
\hline Worm & 1 & 1.4083 & 0.74 & NS \\
\hline Straw & 1 & 0.2083 & 0.11 & NS \\
\hline Worm x straw & 1 & 1.0083 & 0.53 & NS \\
\hline Error & 8 & 17.8917 & & \\
\hline
\end{tabular}

- $d f=$ degrees of freedom; ss $=$ sum of squares; $F=F$ value; NS $=$ not significant; $p-p$ value.

out the straw addition did not respond to the earthworm addition. This result suggests that earthworms stimulated additional organic $\mathrm{C}$ mineralization when the organic amendment was present. Earthworms have repeatedly been demonstrated to increase respiration rates in various soils [22-24]; we also observed this effect in land-farm soils amended with wheat straw. It is notable that earthworm survival in land-farm soil without wheat straw was poor (see below), and this could possibly account for the lack of significant earthworm effects on total respiration in these soils.

\section{Earthworm survival}

In the plant growth experiment, earthworm survival over the course of the 45-d incubation was approximately $90 \%$, and all earthworm mortality was accounted for by discovery (inside the growth chamber) of individuals that had escaped from experimental units. No statistical.difference was found between treatments in terms of number of escaped individuals (results not shown).

In the respiration experiment, wheat straw amendment had a significant effect on earthworm survival, over the course of the 150-d incubation. Earthworm survival was significantly greater in straw-treated experimental units, in all soil treatments (Table 2 and Fig. 3). In particular, earthworm survival was zero in land-farm soils with no wheat straw, but was $27 \%$ in straw-amended land-farm soil. This result suggests that organic amendments (such as wheat straw) may be critical to long-term earthworm survival in land-farm soils.

\section{Oil and grease and TPH analyses}

Results from the O\&G and TPH analyses on soils from the long-term incubation were inconclusive (Tables 2 and 3). We found no statistically significant differences in either $O \& G$ or TPH concentrations associated with the earthworm or wheat straw treatments. This finding is interesting, because the two treatments did seem to improve the biological quality of the land-farm soil (Figs. 2 and 3). Several explanations are possible for this observation. First, O\&G and TPH measurements for soil have high intrinsic variability, and land farming rapidly reduces concentrations of petroleum hydrocarbons of lower molecular weight. Thus, the straw and earthworm treatments may have specifically reduced the concentrations of one or more highly toxic petroleum hydrocarbon compounds that accounted for only a small fraction of the TPH mass. In this case, intrinsic variability in measuring $\mathrm{O} \& \mathrm{G}$ or TPH could obscure a real but small, toxicologically important change in actual concentration. Second, the biological improvements in soil quality might have been due to physical changes due to earthworm activity.(e.g., increased soil porosity, or water-holding capacity), rather than to the loss of one or more toxic petroleum hydrocarbon compounds. A third possibility is that the straw or earthworm treatments increased sequestration of one or more inhibitory petroleum hydrocarbon fractions in the soil. In this case, a contaminated soil could be rendered suitable for biological activity, even though the total quantity of petroleum hydrocarbons extractable by use of a strong solvent might not decrease. This situation, referred to as sequestration, has been thoroughly explored elsewhere [2].

\section{CONCLUSIONS}

The results of this study provide what we believe to be preliminary support for the idea that field-scale additions of earthworms along with selected organic amendments (such as wheat straw) might be used to hasten the long-term recovery 


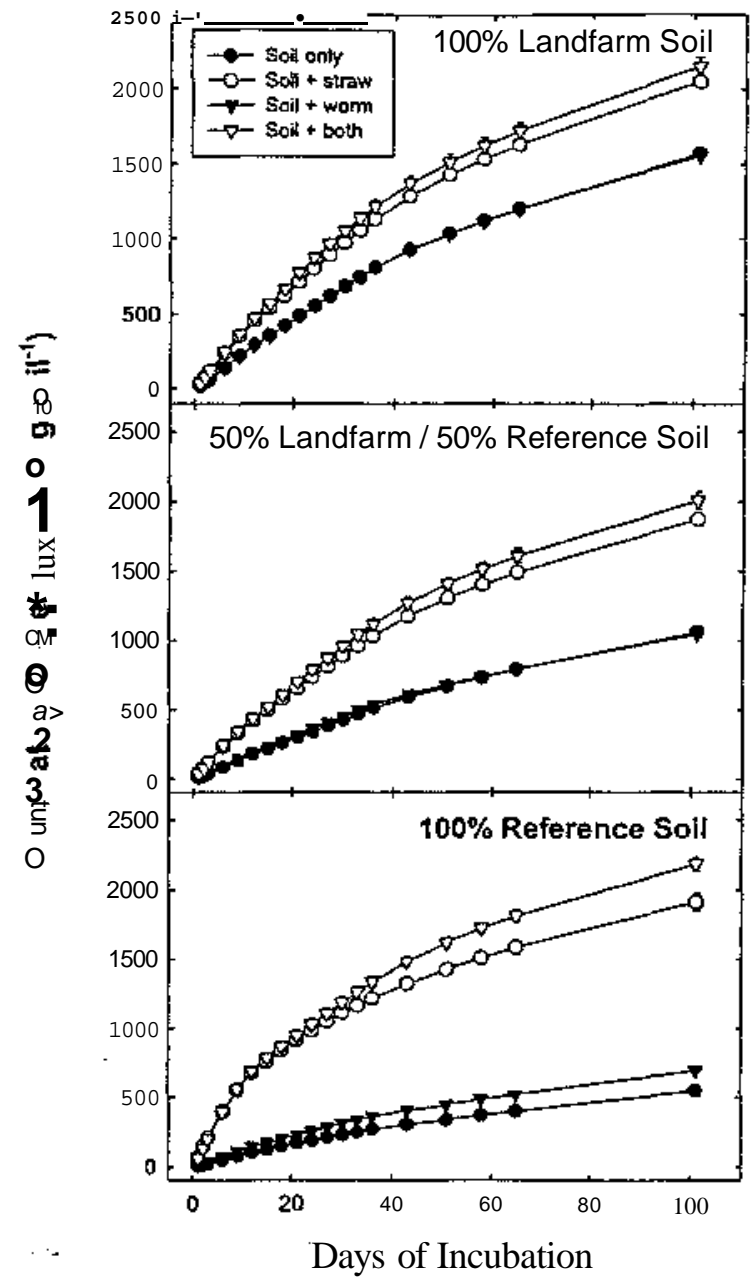

Fig. 2. Cumulative $\mathrm{CO}_{2}$ efflux from earthworm-wheat straw factorial experiment. Symbols represent mean efflux $(\ll=5)$ from experimental units of the indicated treatment. Open symbols represent units with straw amendment, closed symbols represent units without straw amendment. Triangles represent units with earthworms, circles represent units lacking earthworms. Error bars indicate standard error. When no error bars are visible, the standard error is so small that it is obscured by the symbols.

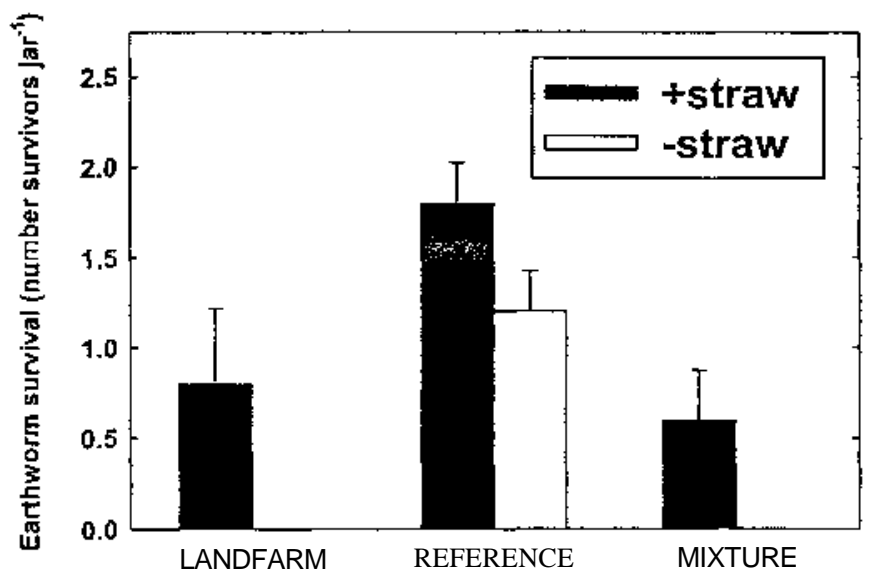

Fig. 3. Effect of wheat straw amendments on earthworm survival in petroleum land-farm soil, non-land-farm reference soil, and a 1:1 mixture of the land-farm and reference soils. Bars represent the mean $(n=5)$ number of survivors (of three initially added earthworms) per jar after $150 \mathrm{~d}$ of incubation. Absence of a bar within a category indicates zero earthworm survival. Error bars indicate standard error.
Table 3. Mean oil and grease $(\mathrm{O} \& \mathrm{G})$ and total petroleum hydrocarbon (TPH) concentrations in petroleum landfarm soils experimentally treated with earthworms, wheat straw, neither (control), or both. Standard error (SE) of each mean value is indicated in parentheses. Also shown are O\&G and TPH concentrations for reference soils similarly incubated with or without wheat straw. For all analyses, $n$ $=3$ and standard errors are shown in parentheses

\begin{tabular}{llcc}
\hline Soil & Treatment & $\begin{array}{c}\text { O\&G (SE) } \\
\text { (g/kg dry soil) }\end{array}$ & $\begin{array}{c}\text { TPH (SE) } \\
(\mathrm{g} / \mathrm{kg} \text { dry soil) }\end{array}$ \\
\hline Landfarm & Control & $603(1.78)$ & $32.7(0.41)$ \\
Landfarm & + Worms & $63.0(2.83)$ & $33.7(1.47)$ \\
Landfarm & + Straw & $60.7(4.26)$ & $32.3(0.82)$ \\
Landfarm & + Both & $55.0(11.1)$ & $29.7(5.93)$ \\
Reference & Control & $0.07(0.06)$ & $0.02(0.002)$ \\
Reference & + Straw & $0.22(0.04)$ & $0.04(0.01)$ \\
\hline
\end{tabular}

of conventionally treated petroleum-contaminated soil. Fieldscale additions of earthworms have been used by other investigators to improve plant growth and soil quality in various reclamation projects $[7,10,11]$, and many studies have reported that the presence of E. fetida is associated with improved plant performance $[15,16]$. Finally, good evidence exists that the roots of certain plant species are associated with soil bacteria capable of metabolizing petroleum hydrocarbons, and although not observed directly in this study, that earthworms themselves may be beneficial in terms of reducing hydrocarbon concentrations [25,26]. Our finding that presence of E. fetida improved the growth of tall fescue roots and shoots (Fig. 1) suggests that appropriate combinations of plant species, earthworm, and wheat straw additions might be incorporated into phytoremediation techniques being developed for lowering the concentrations of petroleum hydrocarbons in land-farm soils.

Acknowledgement-This work was performed while M.A. Callaham was supported by an appointment to the Oak Ridge National Laboratory Post-doctoral Research Associates Program, administered by the Oak Ridge National Laboratory, and the Oak Ridge Institute for Science and Education. This research received support from the U.S. Department of Energy's Fossil Energy Program, through the National Petroleum Technology Office. Oak Ridge National Laboratory is managed by UT-Batelle, LLC, for the U.S. Department of Energy under contract DE-AC0-00OR22725.

\section{REFERENCES}

1. Salanitro JP, Dorn PB, Huesemann MH, Moore KO, Rhoades IA, Jackson LMR, Vipond TE, Western MM, Wisniewski HL. 1997. Crude oil hydrocarbon bioremediation and soil ecotoxicity assessment. Environ Sci Technol 31:1769-1776.

2. Linz DG, Nakles DV, eds. 1997. Environmentally Acceptable Endpoints in Soil: A Risk-Based Approach to Contaminated Site Management Based on Availability of Chemicals in Soil. American Academy of Environmental Engineers, United Book Press, Baltimore, MD.

3. Salanitro JP. 2001. Bioremediation of petroleum hydrocarbons in soil. Adv Agron 72:53-105.

4. Dorn PB. Salanitro JP. 2000. Temporal and ecological assessment of oil contaminated soils before and after bioremediation. Chemosphere 40:419-426.

5. Saterbak A, Toy RJ, Me Main BJ, Williams MP, Dorn PB. 2000. Ecotoxicological and analytical assessment of effects of bioremediation on hydrocarbon containing soils. Environ Toxicol Chem 11:2643-2652.

6. Jones CG, Lawton JH, ShachakM. 1994. Organisms as ecosystem engineers. Oikos 69:373-386.

7. Stockdill SMJ. 1982. Effects of introduced earthworms on the productivity of New Zealand pastures. Pedobiologia 24:29-35.

8. Callaham MA Jr. Hendrix PF. 1998. Impact of earthworms on cycling and uptake of nitrogen in coastal plain forest soils from northwest Florida, USA. Appl Soil Ecol 9:233-239. 
9. Spain AV, Lavelle P, Marrioti A. 1992. Stimulation of plant growth by tropical earthworms. Soil Biol Biochem 24:1629-1633.

10. Curry JP, Cotton DCE 1983. Earthworms and land reclamation. In Satchell JE, ed. Earthworm Ecology, From Darwin to Vermiculture. Chapman \& Hall, London, UK, pp 215-228.

11. Butt KR, Frederickson J, Morris RM. 1997. The earthworm inoculation unit (EIU) technique, an integrated system for cultivation and soil-inoculation of earthworms. Soil Biol Biochem 29: 251-257.

12. Bain SO, Butt KR, Morris RM. 1999. Survival and reproduction of Lumbricus terrestris L. in colliery spoil and sewage sludge. Pedobiologia 43:729-734.

13. Edwards CA. 1998. The use of earthworms in the breakdown and management of organic wastes. In Edwards CA, ed. Earthworm Ecology. St. Lucie, Boca Raton, FL, USA, pp 327-354.

14. Kula H, Larink O. 1998. Tests on the earthworms Eisenia fetida and Aporrectodea caliginosa. In Lokke $\mathrm{H}$, van Gestel CAM, eds, Handbook of Soil Invertebrate Toxicity Tests. John Wiley, New York, NY, USA, pp 95-112.

15. Edwards CA, Burrows I. 1988. The potential of earthworm composts as plant growth media. In Edwards CA, Neuhauser EF, eds, Earthworms in Environmental and Waste Management. SPB Academic Publishing, The Hague, The Netherlands, pp 211-220.

16. Atiyeh RM, Subler S, Edwards CA, Bachman G, Metzger JD, Shuster W. 2000. Effects of vermicomposts and composts on plant" growth in horticultural container media and soil. Pedobiologia 44:579-590.

17. U.S. Environmental Protection Agency. 1996. Test Methods for
Evaluating Solid Waste, Physical/Chemical Methods. Manual SW-846. Washington, DC.

18. Milliken GA, Johnson DE். 1992. Analysis of Messy Data, Vol 1: Designed Experiments. Chapman \& Hall, London, UK.

19. Frey SD, Elliott ET, Paustian K, Peterson GA. 2000. Fungal translocation as a mechanism for soil nitrogen inputs to surface residue decomposition in a no-tillage agroecosystem. Soil Biol Biochem 32:689-698.

20. Corbeels M, Hoffman G, Cleemput OV. 2000. Nitrogen cycling associated with the decomposition of sunflower stalks and wheat straw in a Vertisol. Plant Soil 218:71-82.

21. Cortez J, Hameed R, Bouché MB. 1989. C and N transfer in soil with or without earthworms fed with ${ }^{13} \mathrm{C}$ - and ${ }^{15} \mathrm{~N}$-labelled wheat straw. Soil Biol Biochem 21:491-497.

22. Zhang QL, Hendrix PE 1995. Earthworm (Lumbricus-rubellus and Aporrectodea-caliginosa) effects on carbon flux in soil. Soil Sci Soc Am 7 59:816-823.

23. Saetre P. 1998. Decomposition, microbial community structure, and earthworm effects along a birch-spruce gradient. Ecology 79: 834-846.

24. Haimi J, Einbork M. 1992. Effects of endogeic earthworms on soil processes and plant growth in coniferous forest soil. Biol Fertil Soils 13:6-10.

25. Radwan S, Sorkhoh N, El-Nemr I. 1995. Oil biodegradation around roots. Nature 376:302.

26. Schaefer M. 2001. Earthworms in crude oil contaminated soils: Toxicity tests and effects on crude oil degradation. Contain Soil Sediment Water August 2001:35-37. 